\title{
Lymphocytes Expressing Type 3 Complement Receptors Proliferate in Response to Interleukin 2 and Are the Precursors of Lymphokine-activated Killer Cells
}

\author{
J. Dixon Gray and David A. Horwitz \\ University of Southern California School of Medicine, Clinical Immunology \\ and Rheumatic Disease Section, Los Angeles, California 90033
}

\begin{abstract}
In the absence of antigenic or mitogenic stimulation, certain peripheral blood lymphocytes exhibit proliferative and lymphokine-activated killer (LAK) cell activities when cultured with recombinant IL-2. Both activities were found to be an exclusive property of lymphocytes expressing type 3 complement receptors (CR3) identified by anti-CD11 monoclonal antibodies. CD11 + lymphocytes were then fractionated into three subsets by two-color flow cytometry. These included CD16+ cells, which display distinctive Fc receptors for IgG (CD16). Using anti-CD5, the CD11+ CD16- lymphocytes were separated into non- $T$ cell and $T$ cell subsets. The two non- $T$ cell subsets $(C D 11+C D 16+$ and $C D 11+C D 16-$ CD5-), but not the $\mathrm{T}$ cell subset $(\mathrm{CD11}+\mathrm{CD16}-\mathrm{CD5}+$ ), could proliferate in response to IL-2. Both CD11+ non-T cell subsets, but not the CD11 + T cell subset, had the capacity to mediate natural killer cell activity. However, all three CD11+ lymphocyte subsets were capable of generating LAK activity. These findings are consistent with the concept that two signals are required to stimulate $T$ cells to proliferate. However, at least a small subset of blood $T$ cells can be activated by IL-2 to become LAK cells.
\end{abstract}

\section{Introduction}

IL-2 is a $\mathrm{T}$ cell-derived lymphokine that is the principal growth factor for $\mathrm{T}$ cells $(1,2)$. It has been postulated that IL-2 acts upon $\mathrm{T}$ cells that have received a first signal provided by antigen or mitogen, but not upon resting $T$ cells (3-5). However, in the absence of a first signal, "resting" peripheral blood $\mathrm{T}$ cells have been reported to proliferate in response to IL-2 $(6-11)$. Natural killer (NK) $)^{1}$ cells can proliferate in response to IL-2 $(8,11,12)$, but if $\mathrm{T}$ cells also have this capacity, this finding would conflict with the two-signal theory of $T$ cell activation.

Lymphocytes mediating cytotoxic activity after culture with IL-2 have been called lymphokine-activated killer cells (LAK) (13). This cytotoxicity is non-MHC restricted and the

Received for publication 27 April 1987 and in revised form 2 October 1987.

1. Abbreviations used in this paper: CR3, type 3 complement receptor; IL-2R, IL-2 receptor; LAK, lymphokine-activated killer cell; NK, natural killer; rIL-2, recombinant IL-2; UNF, unfractionated PBMC.

J. Clin. Invest.

(C) The American Society for Clinical Investigation, Inc.

$0021-9738 / 88 / 04 / 1247 / 08 \quad \$ 2.00$

Volume 81, April 1988, 1247-1254 target cells killed include those that are resistant to NK cells (13). The precursors of LAK activity are less well defined. Although LAK activity can be derived from NK cells (11), lymphocyte populations devoid of or depleted of NK activity also demonstrate LAK activity upon culture in the presence of IL-2 $(14,15)$.

In the present study, we have characterized the phenotype of lymphocytes which proliferate in response to IL-2 and which are the precursors of LAK cells. PBMC were separated using anti-CD11 monoclonal antibodies that react with receptors for the $\mathrm{iC} 3 \mathrm{~b}$ component of complement $(16,17)$. These receptors have been called type 3 complement receptors (CR3) (18). Activities associated with the lymphocyte populations identified by anti-CD11 monoclonal antibodies include NK cell activity $(19,20)$, antibody-dependent cellular cytotoxic activity (19), and the suppression of IgG production induced by pokeweed mitogen (21). We report that all IL-2 responsiveness was contained exclusively within the CD11+ lymphocyte populations.

\section{Methods}

$P B M C$. Peripheral blood, obtained from healthy volunteers by venipuncture, was separated by Ficoll-Hypaque (Isolymph; Gallard-Schlesinger Corp., Carle Place, NY) density centrifugation. Mononuclear cells were then washed three times and resuspended in RPMI 1640 medium (Irvine Scientific, Santa Ana, CA) containing glutamine (2 $\mathrm{mM})$, gentamicin $(20 \mu \mathrm{g} / \mathrm{ml})$, and Hepes buffer (10 mM), and supplemented with $10 \%$ human AB serum (Irvine Scientific).

Monoclonal antibodies. The monoclonal antibodies used in this study were anti-CD11 OKM1 (Ortho Diagnostics Systems Inc., Raritan, NJ) or Leu 15 phycoerythrin conjugated (Becton-Dickinson \& Co., Mountain View, CA); anti-CD16 Leu 11a; anti-CD5 Leu 1; and anti-CD25 ( $\alpha$ chain), anti-IL-2 receptor phycoerythrin conjugated (all from Becton-Dickinson \& Co.).

Isolation of lymphocyte subsets. PBMC were stained with monoclonal antibodies under saturating conditions at $4^{\circ} \mathrm{C}$ for $30 \mathrm{~min}$. When PBMC were stained with unconjugated monoclonal antibodies the cells were subsequently incubated with FITC-F $\left(a b^{\prime}\right)_{2}$ sheep anti-mouse IgG (Cappell Laboratories, Cochranville, PA) at $4^{\circ} \mathrm{C}$ for $30 \mathrm{~min}$. Cells were then washed and resuspended at $5 \times 10^{6} / \mathrm{ml}$.

Stained PBMC were analyzed and sorted by flow cytometry using a FACS IV (Becton-Dickinson \& Co.) or a cytofluorograph 50H (Ortho Diagnostics, Westwood, MA). Both flow cytometers are equipped with an argon laser which was operated at $488 \mathrm{~nm}$ for excitation of fluorescein and phycoerythrin. Lymphocyte-sized cells were electronically separated from debris and other cells on the basis of forward and right angle scatter. In all studies with two-color staining, the percentage of cells positive for each marker was confirmed by single-color analysis. When CD11 + CD16- lymphocytes were further fractionated with anti-CD5 monoclonal antibodies, a second sort was performed to isolate the CD5+ and CD5- subsets. Cell sorting provided populations of lymphocytes of $>95 \%$ purity. 
Table I. Composition of CR3 Subsets

\begin{tabular}{lc}
\hline \multicolumn{1}{c}{ Subpopulation } & Total lymphocytes \\
\hline & $\%$ \\
CD11+ & $20 \pm 3$ \\
CD11+CD16+ & $11 \pm 2$ \\
CD11+CD16- & $8 \pm 2$ \\
CD11+CD16-CD5+ & $4 \pm 1$ \\
CD11+CD16-CD5- & $4 \pm 1$ \\
\hline
\end{tabular}

Values derived from the analysis of 10 individuals.

Proliferative activity. PBMC or isolated lymphocyte populations were cultured in the presence or absence of recombinant IL-2 (rIL-2) at $100 \mathrm{U} / \mathrm{ml}$ (Biogen, Cambridge, MA) at 3-4 $\times 10^{4}$ cells/well in the wells of a flat-bottom 96-well microtiter plate (Flow Laboratories, Inc., McLean, VA). Proliferative activity was assessed after $72 \mathrm{~h}$ (unless otherwise stated) by the addition of $1 \mu \mathrm{Ci}\left[{ }^{3} \mathrm{H}\right]$ thymidine (ICN Radiochemicals, Div. of ICN Biomedicals Inc., Irvine, CA) $12 \mathrm{~h}$ before harvesting with an automated sample harvester. Culture in the absence of rlL-2 produced $<500 \mathrm{cpm}$.

Cytotoxic activity. PBMC or isolated lymphocyte populations were cultured in the presence or absence of rIL-2 at $100 \mathrm{U} / \mathrm{ml}$ (Biogen) in the wells of a 24-well plate (Flow Laboratories, Inc.). After 3 to $4 \mathrm{~d}$, cells were harvested, washed, and resuspended in fresh RPMI plus $10 \%$ $A B$ serum. Cytotoxic activity was measured in a $4-h^{51} \mathrm{Cr}$ release assay. Various concentrations of effector cells were added to $2.5 \times 10^{351} \mathrm{Cr}$ labeled K562 or RAJ1 target cells in the wells of a round-bottom 96-well microtiter plate. Effector cells cultured in the absence of rIL2 for $3 \mathrm{~d}$ did not mediate any cytotoxic activity against K562 or RAJ1 cells (data not known). NK activity was measured in a similar assay, except effector cells were not cultured. The amount of cytotoxic activity was determined by the formula: $\%$ cytotoxicity = (experimental release-spontaneous release)/(total release-spontaneous release). Spontaneous release was determined from wells containing no effector cells and total release was obtained from wells containing target cells lysed by $1 \%$ Triton X-100 detergent.

\section{Results}

Composition of CDI1+ subsets. The lymphocyte populations evaluated in this report are shown in Table I. Total CD11+ lymphocytes comprise $\sim 20 \%$ total PBL. The CD16+ lymphocyte (all of which co-express CD11) (22) represent, on average, $11 \%$ of lymphocytes. Of the remaining $8 \% \mathrm{CD} 11+$ CD16- lymphocytes, $\sim 4 \%$ are also CD5+.

Although monocytes also react with anti-CD11, they can be distinguished from lymphocytes by the intensity of fluores- cence staining (22) in addition to light scatter characteristics. Peroxidase staining of sorted CD11 + lymphocytes, as a further check for monocytes, revealed that all populations were $<5 \%$ positive.

Lymphocyte subsets that proliferate in response to IL-2. In preliminary experiments, PBMC were incubated with $10-10,000 \mathrm{U} / \mathrm{ml}$ of IL-2 for $3 \mathrm{~d}$. The proliferative response observed with $100 \mathrm{U} / \mathrm{ml}$ was at least $80 \%$ of the maximal response observed at higher concentrations, and $100 \mathrm{U} / \mathrm{ml}$ was selected for further studies unless stated otherwise.

Consistent with the observations of others (6-11), PBMC cultured for $3 \mathrm{~d}$ in the presence of rIL-2, in the absence of any other mitogenic or antigenic stimulus, exhibit proliferative activity (Table II).

To define the lymphocyte population(s) mediating this proliferative activity, lymphocytes were sorted into CD11+ and CD11- populations using anti-CD11 monoclonal antibodies. Lymphocytes stained with anti-CD11 did not proliferate in the absence of IL-2 and virtually identical proliferative activity was observed between PBMC and PBMC stained with the anti-CD11 monoclonal antibodies (data not shown). Therefore, the anti-CD11 monoclonal antibody itself is not an activation signal. In the three experiments shown in Table II, proliferation in response to IL-2 was detectable only in the CD11+ population. This experiment was repeated with cells from seven other donors, and in only one case was proliferative activity detected in the CD11- population. The PBMC from the latter donor were used to determine whether the IL-2 receptor recognized by anti-TAC was required for proliferative activity. CD11+ and CD11- cell fractions from this donor were then stained with anti-IL-2 receptor (IL-2R), and the IL-2R-positive cells were removed by cell sorting. This procedure markedly reduced the proliferative activity of CD11lymphocytes, but had no significant effect on CD11+ cells (Table III).

The unresponsiveness of the CD11- lymphocytes was not simply due to a lack of accessory cells. The addition of adherent cells, highly enriched for monocytes, did not result in any proliferative response to IL-2 by the CD11- lymphocytes (Table IV). In this experiment the CD11+ lymphocytes exhibited a highly augmented proliferative activity compared with the activity of unfractionated PBMC. In six experiments, either IL-2 or PHA was added to CD11- cells: in each case the CD11 - cells did not proliferate in response to IL-2, but the expected response to PHA was observed (results not shown).

Lymphocytes expressing CR3 are phenotypically heterogeneous and co-express surface determinants associated with $T$ cells or NK cells (22-24). Approximately $60 \%$ of CD11+ lym-

Table II. Proliferative Response of Lymphocytes Cultured in the Presence of IL-2

\begin{tabular}{|c|c|c|c|c|c|c|}
\hline \multirow[b]{3}{*}{ Experiment } & \multicolumn{6}{|c|}{$\left[{ }^{3} \mathrm{H}\right]$ Thymidine uptake } \\
\hline & \multicolumn{2}{|c|}{ Unfractionated } & \multicolumn{2}{|c|}{ CD11- subsets } & \multicolumn{2}{|c|}{ CD11+ subsets } \\
\hline & Medium & rIL-2 & Medium & rIL-2 & Medium & rIL-2 \\
\hline A & $29 \pm 68$ & $11,995 \pm 2,930$ & $251 \pm 106$ & $206 \pm 14$ & $323 \pm 47$ & $8,147 \pm 1,362$ \\
\hline B & $98 \pm 19$ & $3,366 \pm 134$ & $213 \pm 88$ & $306 \pm 10$ & $155 \pm 41$ & $2,989 \pm 45$ \\
\hline C & $591 \pm 135$ & $12,479 \pm 1,301$ & $501 \pm 213$ & $411 \pm 29$ & $455 \pm 95$ & $10,780 \pm 807$ \\
\hline Mean & $328 \pm 74$ & $9,280 \pm 1,544$ & $322 \pm 136$ & $308 \pm 18$ & $311 \pm 60$ & $7,305 \pm 738$ \\
\hline
\end{tabular}


Table III. Proliferative Activity of Lymphocytes Depleted of IL-2R (CD25)-positive Cells

\begin{tabular}{lrrrr}
\hline \multirow{2}{*}{$\begin{array}{l}\text { Lymphocyte } \\
\text { subsets }\end{array}$} & rIL-2 & \multicolumn{2}{l}{ IL-2R $\alpha$ chain-depleted } & \\
\cline { 3 - 4 } & $U / m l$ & & + & $P$ value \\
\hline & & & & \\
CD11- & 0 & 143 & 136 & NS \\
& 100 & 1,884 & 538 & 0.03 \\
CD11+ & 1,000 & 3,140 & 1,078 & 0.03 \\
& 100 & 173 & 128 & NS \\
& 1,000 & 9,637 & 8,657 & NS \\
& & & 9,918 & NS \\
\hline
\end{tabular}

Lymphocyte subsets were cultured in the presence or absence of either 100 or $1,000 \mathrm{U} / \mathrm{ml}$ of rIL-2. In some experiments lymphocytes expressing the CD25 ( $\alpha$ chain) subunit of the IL-2R were stained and depleted by flow cytometry. Tritiated thymidine incorporation was assessed after $72 \mathrm{~h}$ and counts per minute are given. In both CD11+ and CD11- the percentage of IL-2R-positive cells was $2 \%$.

phocytes also express Fc receptors for IgG, which are detectable by anti-CD16 monoclonal antibodies that define a population of lymphocytes highly enriched in NK activity (25-27). To determine whether the IL-2-induced proliferative activity was mediated by NK-associated CD11+ lymphocytes, PBMC were sorted to provide populations of CD11+ CD16+, CD11+ CD16-, and CD11- (CD16-) lymphocytes. Both CD16+ and CD16- subsets of CD11+ lymphocytes demonstrated proliferative activity upon culture in the presence of IL-2 (Fig. 1). As already noted CD11- lymphocytes did not respond to IL-2.

It was possible that the difference in proliferative activity of the lymphocyte populations varied depending on the kinetics of responses to IL-2. To test this, sorted populations of CD11+ CD16+, CD11+ CD16-, and CD11- lymphocytes were cultured in the presence of rIL-2 and assessed for proliferative activity at various times. The proliferative activity of the IL-2-responsive populations (CD11+ CD16-, CD11+ $\mathrm{CD} 16+$ ) was greater at day 6 than at day 3 (Table V). With one exception, proliferation of the CD11+ CD16- subset was greater than that observed with unfractionated or CD11+ CD16+ lymphocytes. At day 6 there was small, but significant proliferative activity of the CD11- cells.
Approximately $18 \%$ of CD11+ lymphocytes co-express pan $T$ markers recognized by anti-CD5 or anti-CD3 monoclonal antibodies (22). With rare exceptions, CD5 and CD3 are expressed exclusively in the CD16- subset (27-29). To further identify the CD11+ IL-2 responsive cells, the CD11+ CD16lymphocytes were further sorted into CD5+ and CD5- fractions. All populations of lymphocytes were then cultured in the presence of rIL-2 and assayed for proliferative activity after $3 \mathrm{~d}$ of culture. In the experiment shown in Fig. 2, proliferative activity was only detected in the CD5- subset, although this was always lower than that of the CD11+CD16- population. Similar results were observed in two other experiments. In these studies there was no significant proliferative activity detected in the CD5+ subset after $7 \mathrm{~d}$ of culture (data not shown).

Cytotoxic activity of IL-2-cultured lymphocytes. In addition to proliferative activity, human PBMC cultured in IL-2 can kill NK-sensitive and NK-resistant target cells. The mediators of this cytotoxic activity have been called LAK cells (13). To determine whether lymphocyte subsets that proliferate in response to IL-2 are also the precursors of LAK cells, sorted populations of $\mathrm{CD} 11+\mathrm{CD} 16+, \mathrm{CD} 11+\mathrm{CD} 16-$, and $\mathrm{CD} 11-$ lymphocytes were cultured in the presence of rIL-2. After $4 \mathrm{~d}$ of culture cells were assayed for cytotoxic activity against K562 (NK susceptible) and RAJ1 (NK resistant) target cells (Fig. 3). Both CD11+ subsets were cytolytic to K562 and RAJ1, whereas the CD11- lymphocytes were noncytotoxic. These experiments were repeated four times with similar results. The anti-CD11 and/or anti-CD16 monoclonal antibodies did not activate NK cells, since PBM stained with either or both monoclonal antibodies did not have any increased cytotoxic activity in NK or LAK assays as compared with unstained PBMC (data not shown). This finding was consistent with similar studies with anti-CD11 reported previously (19).

Relationship of IL-2-responsive lymphocytes to NK cells. As lymphocytes reactive with anti-CD16 monoclonal antibodies are associated with NK activity $(25,27)$, the results of Fig. 3 were initially interpreted as an IL-2-induced augmentation of NK activity by CD11+CD16+ lymphocytes and the induction by IL-2 of cytotoxic activity in the CD11+ CD16population. This possibility was tested by assaying the sorted lymphocyte populations for cytolytic activity against K562 before culture (Fig. 4). Cytotoxic activity was highly enriched in the CD11+ CD16+ lymphocyte fraction. However, the CD11+ CD16- fraction also contained lymphocytes that were cytotoxic to $\mathrm{K} 562$. These results suggested that cytotoxic activ-

Table IV. Accessory Cells Are not Required for IL-2-induced Lymphocyte Proliferation

\begin{tabular}{|c|c|c|c|c|}
\hline Cell population & 100 U IL-2 & $1,000 \cup \mathrm{IL}-2$ & 100 U IL-2 & 1,000 U IL-2 \\
\hline $\mathrm{CD} 11+$ & $25,262 \pm 2,687$ & $30,985 \pm 1,720$ & $25,398 \pm 2,401$ & $33,047 \pm 726$ \\
\hline CD11- & $219 \pm 30$ & $234 \pm 70$ & $473 \pm 160$ & $1,479 \pm 386$ \\
\hline
\end{tabular}

Populations of lymphocytes were cultured for $6 \mathrm{~d}$ in the presence or absence of the indicated concentrations of rIL-2. Some cultures contained $10 \%$ irradiated $(1,500 \mathrm{rad})$ plastic adherent cells as a source of accessory cells. Values given represent tritiated thymidine uptake in counts per minute \pm standard error of the mean. Uptake by lymphocytes cultured in medium alone was $<500$. * ND, Not done. 


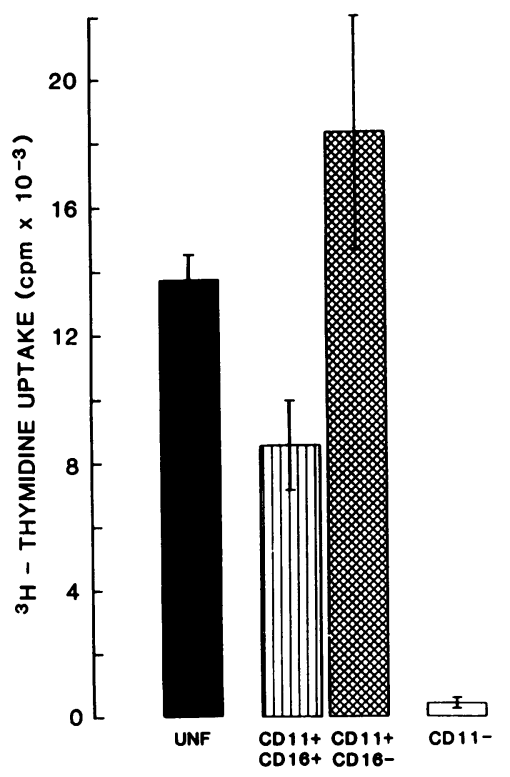

LYMPHOCYTE SUBPOPULATION
Figure 1. The various lymphocyte populations indicated were added to the wells of microtiter plates at $4 \times 10^{4}$ cells/ well. Cells were cultured in the presence of rIL-2 at $100 \mathrm{U} / \mathrm{ml}$ for $72 \mathrm{~h}$ with $\left[{ }^{3} \mathrm{H}\right] \mathrm{TdR}$ added for the last $18 \mathrm{~h}$ of the culture. Indicated is the mean \pm SEM proliferative activity. UNF, Unfractionated PBMC.

ity, after culture in IL-2, results from lymphocyte populations presumably capable of mediating NK activity.

To further define the CD11+ CD16- lymphocytes mediating NK activity, cells were sorted into CD5+ and CD5subsets and assayed for NK activity (Fig. 5 and Fig. $6 A$ ). This cytotoxic activity was detectable only in the CD5- fraction of the CD11+ CD16- lymphocytes. No cytotoxic activity was found in the CD11+ CD16-CD5+ or CD11- populations. No effect on the level of NK activity was observed when PBL stained with anti-CD5 were assayed, indicating that anti-CD5 by itself did not result in any modulation of NK activity.

Each of the sorted lymphocyte populations was then assessed for cytotoxic activity against K562 (Fig. 6 B) and RAJ1 (Fig. $6 C$ ) after culture in the presence of IL-2. All the CD11+ fractions mediating endogenous NK activity (Fig. $6 A$ ) were also cytotoxic after culture in IL-2 (Fig. $6 B$ and $C$ ). However, the CD11+CD16-CD5+ subset, which did not have endoge-

nous NK activity, exhibited cytotoxic activity against both K562 and RAJ1 after culture in IL-2. Similar results were obtained in two other experiments. Moreover, when assayed for cytotoxic activity against another NK-resistant cell line, Daudi, the same CD11+ lymphocyte subpopulations mediated LAK cell activity in three separate experiments. One such experiment is shown in Table VI. Thus, after culture with IL-2, all three CD11+ lymphocyte subpopulations had cytotoxic activity against NK-susceptible and NK-resistant target cells.

\section{Discussion}

The lymphocyte populations that respond to IL-2 in shortterm cultures in the absence of any mitogenic or antigenic stimulus have been identified. Whether we assayed responsiveness to IL-2 as proliferative activity or cytotoxic activity, this was an exclusive characteristic of lymphocytes displaying CR3 as detected by anti-CD11 monoclonal antibodies. Two non-T CD11+ lymphocyte subsets responding to IL-2 were identified. These were $\mathrm{CD} 16+$ lymphocytes with $\mathrm{Fc}$ receptors for IgG $(26,27)$, and CD16- CD5- cells. T cells in the CD11fraction and CD11+CD5+ lymphocytes did not proliferate in response to IL-2, a finding consistent with the two-signal concept of $\mathrm{T}$ cell activation. After $7 \mathrm{~d}$ of culture, there was small but significant proliferative activity by CD11-lymphocytes, but this finding was possibly associated with the generation of an autologous mixed lymphocyte culture or by activation due to serum components.

While proliferation in the presence of IL-2 was found to be an exclusive property of $\mathrm{CD} 11+$ lymphocytes, this population of lymphocytes are heterogeneous in their expression of other cell surface antigens. Approximately half of the CD11+ lymphocytes co-express the CD2 antigen or sheep erythrocyte receptor $(23,24)$. Therefore, previous studies demonstrating IL-2-induced proliferative activity in both erythrocyte-positive and erythrocyte-negative fractions would not be unexpected, and probably does not reflect $T$ cell proliferation $(6,7)$. As approximately one-third of CD11+ lymphocytes also express the CD8 antigen, the reported proliferation of both

Table V. Lymphocyte Subsets That Proliferate in Response to IL-2 [ $\left.{ }^{3} H\right]$ Thymidine Uptake

\begin{tabular}{|c|c|c|c|c|}
\hline Experiment & Unfractionated & $\mathrm{CD} 11+\mathrm{CD} 16+$ & $\mathrm{CD} 11+\mathrm{CD} 16-$ & CD11-CD16- \\
\hline \multicolumn{5}{|c|}{ 3-d incubation period } \\
\hline A & $1,580 \pm 32$ & $4,165 \pm 407$ & $11,499 \pm 768$ & $435 \pm 69$ \\
\hline B & ND & ND & ND & ND \\
\hline $\mathrm{C}$ & $4,284 \pm 271$ & $3,305 \pm 382$ & $11,690 \pm 482$ & $311 \pm 53$ \\
\hline Mean & $2,932 \pm 151$ & $3,735 \pm 395$ & $11,594 \pm 625$ & $373 \pm 51$ \\
\hline \multicolumn{5}{|c|}{ 6-d incubation period } \\
\hline A & $13,612 \pm 2,968$ & $18,510 \pm 858$ & $57,258 \pm 5,808$ & $1,442 \pm 356$ \\
\hline B & $18,825 \pm 771$ & $8,384 \pm 714$ & $36,840 \pm 2,262$ & $1,283 \pm 199$ \\
\hline $\mathrm{C}$ & $79,129 \pm 5,016$ & $18,778 \pm 3,169$ & $74,711 \pm 2,426$ & $1,541 \pm 385$ \\
\hline Mean & $31,189 \pm 2,918$ & $15,224 \pm 1,580$ & $56,270 \pm 3,499$ & $1,422 \pm 313$ \\
\hline
\end{tabular}

PBMC or sorted lymphocyte subsets were incubated for the indicated days with IL-2 $(100 \mathrm{U} / \mathrm{ml})$ or medium alone. Tritiated thymidine uptake by unstimulated lymphocytes ranged between 200 and $600 \mathrm{cpm}$ after $6 \mathrm{~d}$ of culture. 


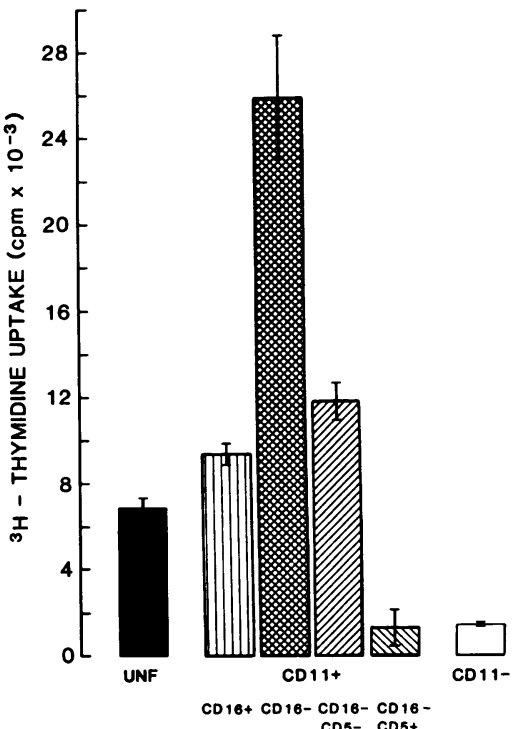

LYMPHOCYTE SUBPOPULATION
Figure 2. See legend to Fig. 1.

CD8+ and CD8- lymphocytes is again consistent with our findings $(9,11)$. Finally, as only $4-5 \%$ of CD11+ lymphocytes co-express the CD4 antigen (22), the observation that CD4+ lymphocytes do not proliferate in response to IL-2 is also consistent with our results $(6,11)$.

Interestingly, in the present study the proliferative activity of the CD5- subset of CD11+ CD16- lymphocytes was always less than that of the unfractionated CD11+ CD16population. This finding suggests that the CD5+ subset, although demonstrating little or no proliferation in the presence of IL-2, was capable of amplifying the response to IL-2 of the CD5 - subset. Itoh et al. also documented the ability of an IL-2-nonresponsive population to augment the proliferation of an IL-2-responsive population (11).

In addition to the proliferative activity, LAK activity was an exclusive property of CD11+ lymphocytes. Grimm et al. reported previously that LAK activity could develop from CD11- precursors (14), but these conclusions were based

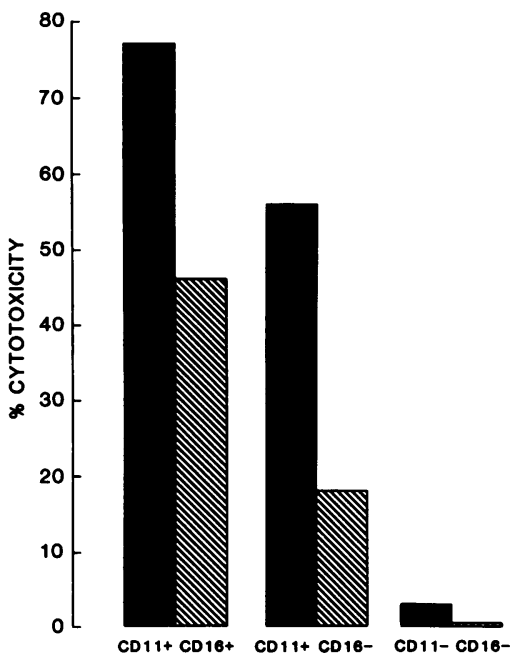

LYMPHOCYTE SUBPOPULATION
Figure 3. The lymphocyte populations indicated were isolated and then cultured in the presence of rIL-2 at 100 $\mathrm{U} / \mathrm{ml}$. After $3 \mathrm{~d}$, cells were assayed for cytotoxic activity against K562 (filled column) or RAJ1 (hatched column) tumor target cells in a 4-h ${ }^{51} \mathrm{Cr}$ release assay at an effector to target ratio of $1: 1$. Columns show the percentage of cytotoxic activity.

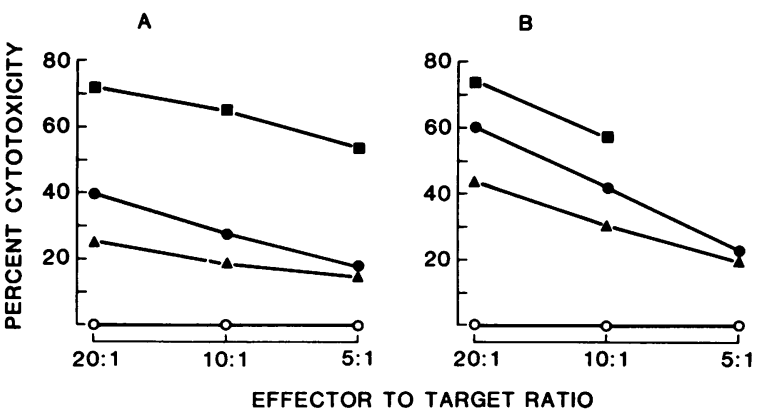

Figure 4. CD11+ lymphocyte subsets mediate NK activity. PBMC

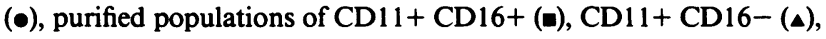
or CD11-CD16- (0) lymphocytes were assayed for cytotoxic activity against $\mathrm{K} 562$ at the effector to target ratios indicated. The results of two different experiments $(A$ and $B)$ are shown.

upon complement-dependent cytolysis of CD11+ cells using OKM1, a method much less efficient than the flow cytometry procedure used in the present studies. Consistent with our findings, Itoh et al. found that cytotoxic activity after culture in IL-2 was attributable to CD16+ lymphocytes (11). However, our studies also revealed that CD16- (CD11+) lymphocytes mediate cytotoxic activity after culture in IL- 2 . The inability of Itoh et al. (11) to detect cytotoxic activity in the CD16- population was possibly due to the relatively low concentration (10 U) of rIL-2 used.

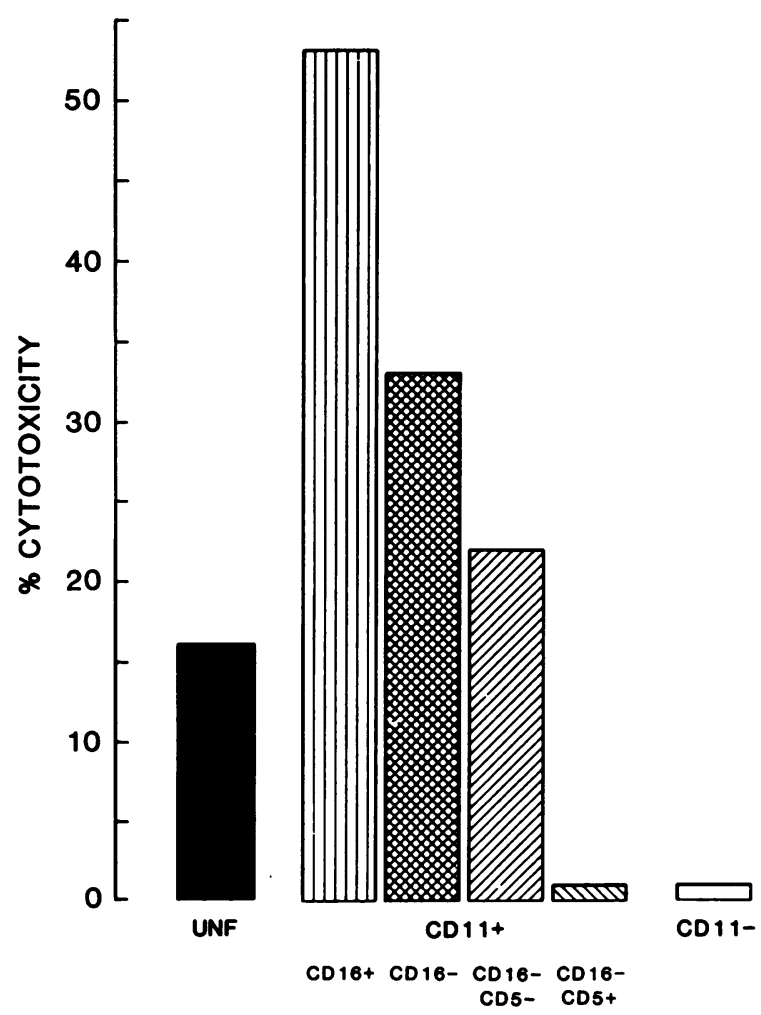

\section{LYMPHOCYTE SUBPOPULATION}

Figure 5. PBMC or the indicated purified lymphocyte subpopulations were assayed for cytotoxic activity against $\mathrm{K} 562$ in a 4-h ${ }^{51} \mathrm{Cr}$ release assay at an effector to target ratio of 15:1. 


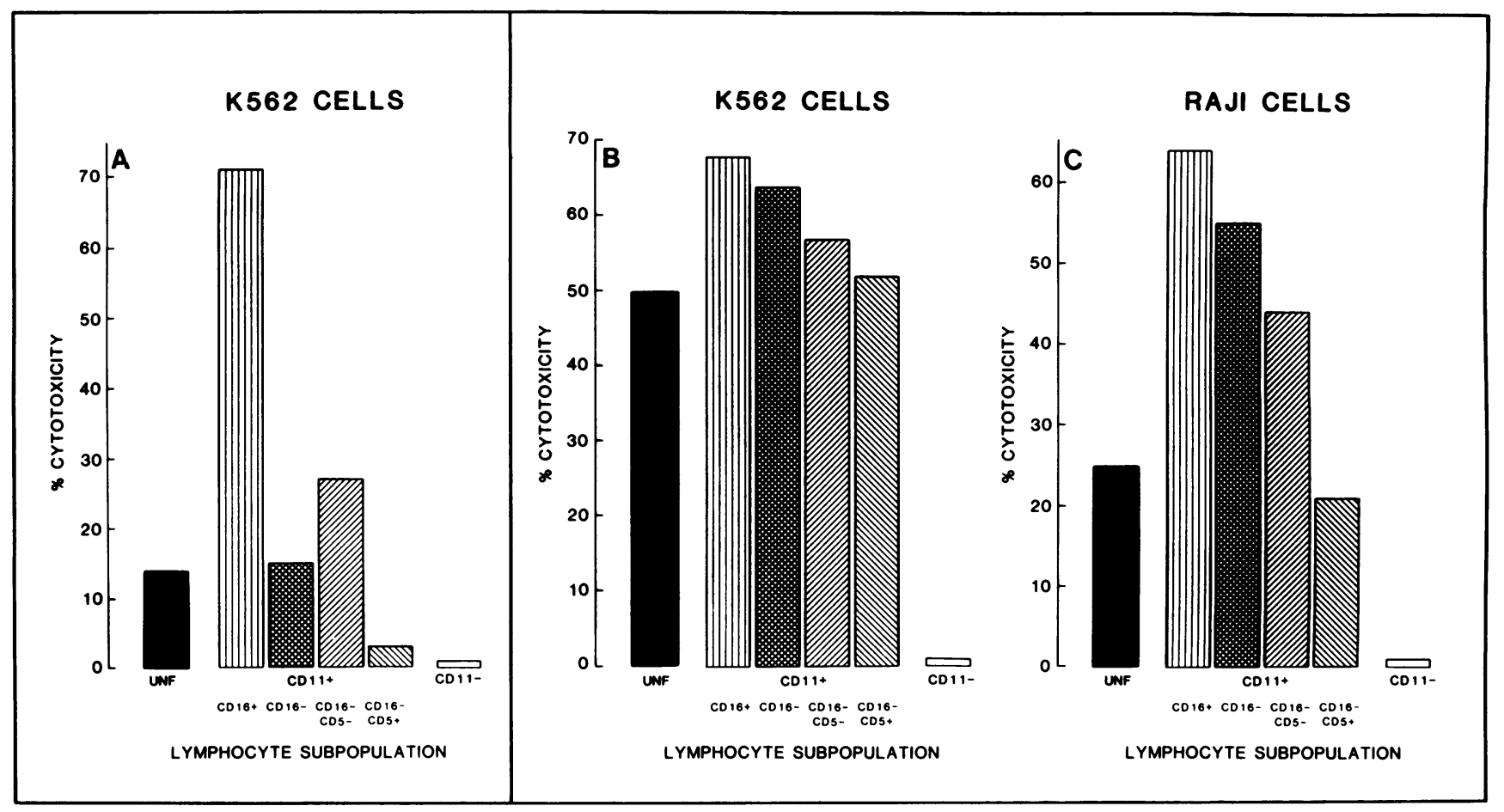

Figure 6. The lymphocyte subpopulations indicated were assayed for cytotoxic activity against K 562 on the day of isolation $(\dot{A})$ or were cultured for $3 \mathrm{~d}$ in the presence of rIL-2 at $100 \mathrm{U} / \mathrm{ml}$, then assayed for cytotoxic activity against $\mathrm{K} 562(B)$ or RAJ1 $(C)$ tumor target cells. In $A$ the effector to target ratio shown is $20: 1$, whereas in $B$ and $C$ an effector to target ratio of $10: 1$ is shown.

Although the CD5+ subset of CR3+ lymphocytes did not proliferate in response to IL-2 or mediate NK activity, this subset did develop LAK activity in the presence of IL-2. This minor $\mathrm{T}$ cell subset was the only $\mathrm{T}$ cell subset capable of responding to IL-2. These results differ from the observations of Phillips and Lanier, who reported that all the precursors of LAK cells in blood were non-T cells (30). These workers found that CD5+ Leu 19+ cultured with IL-2 killed NK-susceptible, but not NK-resistant, target cells (30). Possible explanations of the differences between the observations of Phillips and Lanier (30) and our findings may reflect the target cells used and the time of culture in the presence of IL-2. Phillips and Lanier (30) cultured cells for $7 \mathrm{~d}$, whereas we have found

Table VI. Cytotoxic Activity of Lymphocyte Subsets against Daudi Cells

\begin{tabular}{lrrr} 
& \multicolumn{3}{c}{ Effector to target cell ratio } \\
\cline { 2 - 4 } \multicolumn{1}{c}{ Cell subset } & $20: 1$ & $10: 1$ & $5: 1$ \\
\hline Unfractionated & 63 & 53 & 45 \\
CD11+ CD16+ & 57 & 44 & 27 \\
CD11+ CD16- & 65 & 44 & 27 \\
CD11- CD16- & 3 & 0 & 0 \\
CD11+ CD16- CD5+ & 54 & 41 & 36 \\
CD11+ CD16- CD5- & 70 & 53 & 46 \\
\hline
\end{tabular}

Various lymphocyte populations were cultured in the presence of $100 \mathrm{U}$ rIL-2. After $3 \mathrm{~d}$ lymphocytes were assayed for cytotoxicity against Daudi target cells in a $4-\mathrm{h}{ }^{51} \mathrm{Cr}$ release assay. that 3-5 d cultures generate the maximal cytotoxic activity against both NK-susceptible and NK-resistant target cells.

Recently, Damle et al. (31) reported that IL-2-activated killer cell activity could be derived from populations consisting of $T$ cells as well as non-T cells. Since CD11 is expressed on both $\mathrm{T}$ and non-T cells, it is possible that these IL-2-responsive cells are also CD11+.

The present studies revealed two phenotypically identifable lymphocyte populations capable of mediating NK activity. Besides the highly active CD11+CD16+ population, NK activity was also detected with CD11+ CD16- effector cells. Upon further fractionation of the latter population into CD5+ and CD5 - subsets, cytotoxic activity was found only in the CD5- subset. Recently, Lanier et al. also reported phenotypic heterogeneity in NK effector cells, with activity being detected in CD16+ and CD16- populations (32). However, these authors demonstrated that NK activity of the latter population was associated with a CD5+ subset. This apparent conflict with our findings may reflect the different monoclonal antibodies used to isolate the various lymphocyte populations. The monoclonal antibody used by Lanier et al. (32), Leu 19, identifies a population of lymphocytes of which $\sim 80 \%$ co-express the CR3 receptor (data not shown). Thus, $\sim 20 \%$ of Leu $19+$ lymphocytes are CD11-. It is, therefore, possible that a CD5+ subset of NK cells is contained within the Leu 19+ CD11-population.

An important functional difference between CD11+ and CD11-lymphocytes is the role of the IL-2 receptor recognized by anti-CD 25 monoclonal antibodies. On one occasion where we did observe spontaneous proliferation of CD11- lymphocytes in response to IL-2, this activity was reduced by remov- 
ing cells stained by anti-CD25. Removal of this subset from CD11+ lymphocytes did not affect proliferation in response to IL-2.

Recently, a 70-kD IL-2 binding protein distinct from the CD25 (Tac) IL-2 receptor has been described which binds IL-2 with an intermediate affinity (33-36). It has been reported that natural killer cells $(35,37)$ and resting $T$ cells $(37)$ can express this $70-\mathrm{kD}$ protein. Our studies would suggest that expression of the 70-kD protein on CD11+ lymphocytes is sufficient for IL-2 responsiveness, whereas expression of this molecule by itself is insufficient for responsiveness by CD11-lymphocytes.

\section{Acknowledgments}

The authors wish to thank Ms. Lille Hsu for excellent technical assistance and Ms. Vickie Wong and Ms. Alma Wade for skillful operation of the flow cytometer. We also thank Dr. William Stohl for his helpful comments. Ms. Jewelean McCovery and Ms. Kathy Schaivone are thanked for their assistance with the preparation of the manuscript.

This work was supported in part by grants from National Institute of Health (AM-29846) and the Hastings Foundation.

\section{References}

1. Smith, K. A., and F. Ruscetti. 1981. T cell growth factor and the culture of cloned functional T cells. Adv. Immunol. 31:137-175.

2. Smith, K. A. 1984. Interleukin 2. Ann. Rev. Immunol. 2:319333.

3. Cantrell, D., and K. A. Smith. 1983. Transient expression of interleukin 2 receptors. Consequences for T cell growth. J. Exp. Med. 158:1895-1911.

4. Depper, J. M., W. J. Leonard, M. Kronke, P. D. Noguchi, R. E. Cunningham, T. A. Waldman, and W. C. Greene. 1984. Regulation of interleukin 2 expression: effects of phorbol diester phospholipase C and reexposure to lectin or antigen. J. Immunol. 133:3054-3061.

5. Hemler, M., M. Brenner, J. McLean, and J. Strominger. 1984. Antigenic stimulation regulates the level of expression of interleukin 2 receptor on human T cells. Proc. Natl. Acad. Sci. USA. 81:2172-2175.

6. Lifson, J., A. Raubitschek, Benike, K. Koths, A. Ammann, P. Sondel, and E. Engleman. 1986. Purified interleukin 2 induces proliferation of fresh human lymphocytes in the absence of exogenous stimuli. J. Biol. Response Mod. 5:61-72.

7. Hammer, S. M., and J. M. Gillis. 1986. Effects of recombinant interleukin 2 on resting human T lymphocytes. J. Biol. Response Mod. 5:36-44.

8. Talmadge, J. E., R. H. Wiltrout, D. F. Counts, R. B. Herberman, T. McDonald, and J. R. Ortaldo. 1986. Proliferation of human peripheral blood lymphocytes induced by recombinant interleukin 2: contribution of large granular lymphocytes and T lymphocytes. Cell Immunol. 102:261-271.

9. Bich-Thuy, L. T., H. C. Lane, and A. S. Fauci. 1986. Recombinant interleukin 2 induced polyclonal proliferation of in vitro unstimulated human peripheral blood lymphocytes. Cell Immunol. 98:396410.

10. Taylor, DS., J. A. Kern, and P. C. Nowell. 1986. Il-2 alone is mitogenic only for TAC-positive lymphocytes in human peripheral blood. J. Immunol. 136:1620-1624.

11. Itoh, K., A. B. Tilden, K. Kumagai, and C. M. Balch. 1985. Leu $11+$ lymphocytes with natural killer (NK) activity are precursors of recombinant interleukin 2 (rIL-2) induced activated killer (AK) cells. J. Immunol. 134:802-807.

12. Trinchieri, G., M. Matsumoto-Kobayashi, S. C. Clark, J. Seehra, L. London, and B. Perussia. 1984. Response of resting human peripheral blood natural killer cells to interleukin 2. J. Exp. Med. 160:1147-1169.

13. Grimm, E. A., A. Mazumder, H. Z. Zhang, and S. A. Rosenberg. 1982. Lymphokine activated killer cell phenomenon. Lysis of natural killer resistant fresh solid tumor cells by interleukin 2 activated autologous human peripheral blood lymphocytes. J. Exp. Med. 155:1823-1841.

14. Grimm, E. A., K. M. Ramsey, A. Mazumder, D. J. Wilson, J. Y. Djeu, and S. A. Rosenberg. 1983. Lymphokine activated killer cells phenomenon. II. Precursor phenotype is serologically distinct from peripheral lymphocytes memory cytotoxic thymus derived natural killer cells. J. Exp. Med. 157:884-897.

15. Gray, J. D., H. Shau, and S. H. Golub. 1985. Functional studies on the precursors of human lymphokine activated killer cells. Cell Immunol. 96:338-350.

16. Wright, S. D., P. E. Rao, W. C. Van Voorhis, L. S. Craigmyle, K. lida, M. A. Talle, E. F. Westberg, G. Goldstein, and S. C. Silverstein. 1983. Identification of the $\mathrm{C} 3 \mathrm{bi}$ receptor of human leukocytes and macrophages by using monoclonal antibodies. Proc. Natl. Acad. Sci. USA. 80:5699-5703.

17. Ross, G. D., J. A. Cain, and P. Lachmann. 1985. Membrane complemented receptor type three (CR3) has lectin-like properties analogous to bovine conglutinin and functions as a receptor for zymosan and rabbit erythrocytes as well as a receptor for iC3b. J. Immunol. 134:3307-3315.

18. Ross, G. D., and M. E. Medof. 1985. Membrane complement receptors specific for bound fragments of C3. Adv. Immunol. 37:217267.

19. Kay, H. D., and D. A. Horwitz. 1980. Evidence by reactivity with hybridoma antibodies for a probable myeloid origin of peripheral blood cells active in nature cytotoxicity and antibody-dependent cellmediated cytotoxicity. J. Clin. Invest. 66:847-851.

20. Zarling, J. M., and P. C. Kung. 1980. Monoclonal antibodies which distinguish between human NK cells and cytotoxic T lymphocytes. Nature (Lond.). 288:394-396.

21. Abo, W., J. D. Gray, A. C. Bakke, and D. A. Horwitz. 1987. Studies on human blood lymphocytes with iC3b (type 3) complement receptors. II. Characterization of subsets which regulate pokeweed mitogen-induced lymphocyte proliferation and immunoglobulin synthesis. Clin. Exp. Immunol. 67:544-555.

22. Bakke, A. C., J. D. Gray, W. Abo, F. P. Quismorio, A. Lash, S. M. Cooper, and D. A. Horwitz. 1986. Studies of human blood lymphocytes with iC3b (type 3) complement receptors. I. Granular, Fc-IgG receptor positive and negative subsets in healthy subjects and patients with systemic lypus erythematosus. J. Immunol. 136:12531259.

23. Zarling, J. M., K. A. Clouse, W. E. Biddison, and P. C. Kung. 1981. Phenotypes of human natural killer cells populations detected with monoclonal antibodies. J. Immunol. 127:2575-2580.

24. Griffin, J. D., T. Hercend, R. Beveridge, and S. F. Schlossman. 1983. Characterization of an antigen expressed by human natural killer cells. J. Immunol. 130:2947-2951.

25. Lanier, L. L., A. M. Le, J. H. Phillips, N. L. Warner, and G. F. Babcock. 1983. Subpopulations of human natural killer defined by expression of the Leu 7 (HNK-1) and Leu 11 (NK-15) antigens. $J$. Immunol. 131:1789-1796.

26. Perussia, B., S. Starr, S. Abraham, V. Fanning, and G. Trincheri. 1983. Human natural killer cells analyzed by B73.1, monoclonal antibody blocking Fc receptor functions. I. Characterization of the lymphocyte subsets reactive with B73.1. J. Immunol. 130:2133-2141.

27. Perussia, B., G. G. Trinchieri, A. Jackson, N. L. Warner, J. Faust, H. Rumpold, D. Kraft, and L. L. Lanier. 1984. The Fc receptor for IgG on human natural killer cells: phenotypic, functional and comparative studies with monoclonal antibodies. J. Immunol. 133:180-189.

28. Phillips, J. H., N. Warner, and L. L. Lanier. 1984. Correlation of biophysical properties and cell surface antigenic profile of percoll 
gradient separated human natural killer cells. Nat. Immun. Cell Growth Regul. 3:73-86.

29. Lanier, L. L., T. J. Kripps, and J. H. Phillips. 1985. Functional properties of a unique subset of cytotoxic CD3 + $T$ lymphocytes that express Fc receptors for IgG (CD16/Leu 11 antigen). J. Exp. Med. 162:2089-2106.

30. Phillips, J. H., and L. L. Lanier. 1986. Dissection of the lymphokine activated killer cell phenomenon. Relative contribution of peripheral blood natural killer cells and T lymphocytes to cytolysis. $J$. Exp. Med. 164:814-825.

31. Damle, N. K., L. V. Doyle, and E. C. Bradley. 1986. Interleukin 2-activated human killer cells are derived from phenotypically heterogeneous precursors. J. Immunol. 137:2814-2822.

32. Lanier, L. L., A. M. Le, C. I. Civin, M. R. Loken, and J. H. Phillips. 1986. The relationship of CD16 (Leu 11) and Leu 19 (NKH-1) antigen expression on human peripheral blood NK cells and cytotoxic T lymphocytes. J. Immunol. 136:4480-4486.

33. Sharon, M., R. D. Klausner, B. R. Cullen, C. Chezzonite, R. and W. J. Leonard. 1986. Novel interleukin 2 receptor subunit detected by crosslinking under high affinity conditions. Science. 234:859-863.

34. Tsuido, M., R. W. Kozak, C. K. Goldman, and T. A. Waldmann. 1986. Demonstration of a non-Tac peptide that binds interleukin 2: a potential participant in a multichain interleukin 2 receptor complex. Proc. Natl. Acad. Sci. USA. 83:9694-9698.

35. Teshigawara, K., H. Wang, K. Kato, and K. A. Smith. 1987. Interleukin 2 high-affinity receptor expression requires two distinct binding proteins. J. Exp. Med. 165:223-238.

36. Robb, R. J., C. M. Rusk, J. Yodoi, and W. C. Greene. 1987. An interleukin 2 binding molecule distinct from the Tac protein: analysis of its role in formation of high affinity receptors. Proc. Natl. Acad. Sci. USA. 84:2002-2006.

37. Dukovich, M., Y. Wano, Le Bich-Thuy, P. Katz, B. R. Cullen, J. H. Kehrl, and W. C. Greene. 1987. Identification of a second human interleukin-2 binding protein and its role in the assembly of the high affinity IL-2 receptor. Nature (Lond.). 327:518-522. 